\title{
November 9 Highlights
}

\section{Assuring truth in the courtroom}

Freeman and Nelson note that only members of a relevant specialty can assure truth in medical testimony. They assent that the American Academy of Neurology should require that when its members act as expert witnesses, their testament must be supported by high quality evidence.

see page 1557

In the accompanying editorial, Murray Sagsveen notes that while more could probably be done by specialty societies, the American Academy of Neurology has a carefully defined policy on medical testimony: "The neurologist called upon to provide expert medical testimony should testify only about those subjects for which the neurologist is qualified as an expert by training and experience. Before giving testimony the neurologist should carefully review the relevant records and facts of the case and the prevailing standards of practice. In providing testimony, the neurologist should provide scientifically correct and clinically accurate opinions. Compensation for testimony should be reasonable and commensurate with time and effort spent, and must not be contingent upon outcome."

see page 1555

\section{Evaluation of neuromuscular symptoms in UK Gulf War veterans}

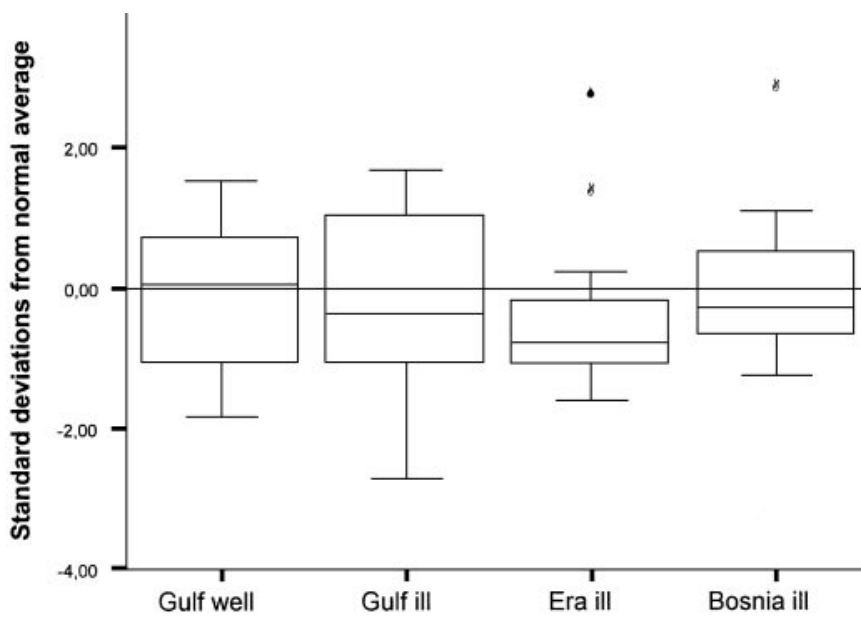

Standardized $Z$ scores for composite maximum voluntary isometric contraction scores by cohort.

This controlled study by Rose et al. shows that complaints of muscle weaknesses and fatigue in Gulf War veterans are not associated with any objective abnormality on quantitative myometry, or with any metabolic muscle defect. However, they found that Gulf-ill veterans did have reduced mitochondrial function.

\section{Subcortical structures and reflexive saccade inhibition}

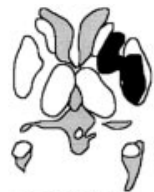

IC3 100/100

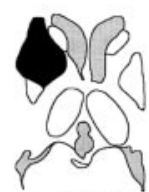

IC4 100/100

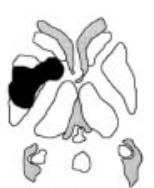

IC5 83/92

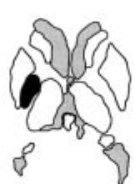

IC7 75/75
Location of lesions in patient with an increased error rate.

Condy et al. studied the antisaccade task in 29 patients with a lesion affecting subcortical structures. Internal capsule but not basal ganglia or thalamic lesions impaired reflexive saccade inhibition, suggesting that this inhibitory function is mainly controlled by a direct prefronto-tectal pathway.

see page 1571

In the accompanying editorial, Zee and Lasker note that the antisaccade task is a useful eye movement paradigm in which a subject has to cancel willfully a reflexive saccade to a suddenly appearing visual stimulus, and then generate a "voluntary" antisaccade saccade in the opposite direction to the mirror location of the original visual target. Errors on the antisaccade task show up at the bedside as mistaken glances at a wiggling finger located in the visual periphery on one side. The dorsolateral prefrontal cortex and the superior colliculus are critical to suppressing unwanted saccades to suddenly appearing targets. Condy et al. show that errors on the antisaccade task can be attributed to a lesion in the specific portion of the internal capsule that transmits information directly from the dorsolateral prefrontal cortex to the superior colliculus and not to lesions in the basal ganglia or thalamus. It remains to be shown if these abnormalities in the antisaccade task can be appreciated at the bedside.

see page 1554

\section{Donepezil improves memory in multiple sclerosis (MS)}

The Krupp et al. single center, 24-week randomized clinical trial of 69 individuals with MS, found that $10 \mathrm{mg}$ daily of donepezil significantly improved memory performance vs placebo.

see page 1579

In the accompanying editorial, Doraiswamy and Rao note that 40-65\% of MS patients experience cognitive dysfunction: primarily impaired recent memory, information processing speed, and sustained attention. They consider the Krupp et al. report a major advance in the search for cognitive-enhancing treatments for MS patients. However, conclusive evidence of efficacy must await replication in a larger study across many centers. Moreover, the study does not answer some critical real world questions: How long to treat and how to tell if the drug is no longer working? Are benefits lost once you stop? Are there withdrawal effects? Are there long term risks? Is treatment cost-effective?

see page 1552 
Neurocysticercosis in the United States

Wallin and Kurtzke reviewed the nearly 1,500 cases of neurocysticercosis reported in the United States over the past two decades. Onset symptoms included seizures (66\%), hydrocephalus (16\%), and headaches (15\%). The majority presented with parenchymal disease (91\%), with the remainder having ventricular cysts (6\%), subarachnoid cysts (2\%), and spinal cysts (0.2\%).

see page 1559

\section{Progression of cognitive impairment in stroke patients}

Subjects from the Sydney Stroke Study cohort were followed up 1 year after their index assessment by Sachdev et al. Stroke patients showed a slow decline in cognitive functioning in the absence of any identified, further cerebrovascular events, although the occurrence of such an event accentuated the decline. Education played a protective role.

see page 1618

\section{VIDEO ALERT}

This issue has a video posted online:

Short-term outpatient EEG video with induction in the diagnosis of psychogenic seizures

S.R. Benbadis, K. Siegrist, W.O. Tatum, L. Heriaud, and K. Anthony

Neurology 2004;63:1728-1730. 


\title{
Neurology
}

\author{
November 9 Highlights \\ Neurology 2004;63;1550-1551 \\ DOI 10.1212/01.WNL.0000146473.55674.D1
}

This information is current as of November 8, 2004

\section{Updated Information \&}

Services

Permissions \& Licensing

Reprints including high resolution figures, can be found at: http://n.neurology.org/content/63/9/1550.full

Information about reproducing this article in parts (figures,tables) or in its entirety can be found online at:

http://www.neurology.org/about/about_the_journal\#permissions

Information about ordering reprints can be found online:

http://n.neurology.org/subscribers/advertise

Neurology ${ }^{\circledR}$ is the official journal of the American Academy of Neurology. Published continuously since 1951, it is now a weekly with 48 issues per year. Copyright. All rights reserved. Print ISSN: 0028-3878. Online ISSN: 1526-632X.

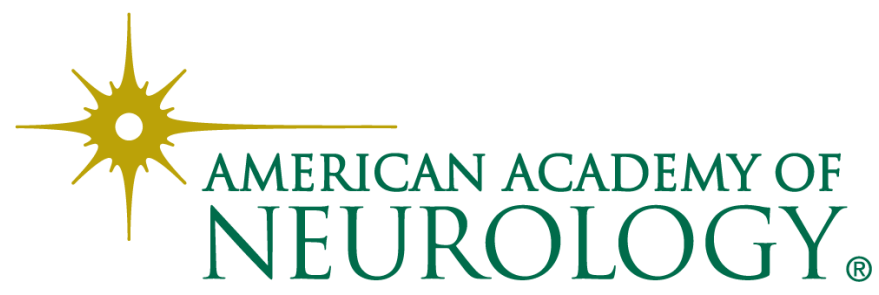

